\title{
0 interminável (falso) debate em torno da obra de Durkheim: de Parsons a Alexander
}

FRANÇOIS PIZARRO NÖEL"

\section{Resumo}

Há alguns anos Jeffrey Alexander (1947-) sucedeu Talcott Parsons (1902-1979) como o sociólogo americano mais influente e, como Parsons, sua obra se construiu primeiramente através de uma reinterpretação crítica dos autores clássicos da sociologia. É, em grande medida, por meio de um estudo dos escritos durkheimianos, que conferem um estatuto particular ao livro As Formas Elementares da Vida Religiosa, que os dois autores elaboraram, cada um a seu modo, uma teoria voluntarista da ação social. Veremos ao longo deste artigo, que, para além das diferenças entre suas interpretações - fundadas sobre diferentes maneiras de identificar as etapas no desenvolvimento do pensamento durkheimiano -, Parsons e Alexander assemelham-se ao reduzir tal pensamento a uma teoria da ação social.

Palavras-chave: Talcott Parsons. Jeffrey Alexander. As Formas Elementares da Vida Religiosa.

*Université du Québec à Montréal, Canadá 


\section{The endless (false) debate around the work of Durkheim: from Parsons to Alexander}

\section{Abstract}

Alexander has succeeded Parsons for some years as the most influential American sociologist and, like Parsons, his work was first constructed by a critical reinterpretation of the classical authors of sociology. It is largely through a study of the Durkheimian writings conferring a special status on the FEVR that the two authors have elaborated, each in their own way, a voluntarist theory of social action. We shall see, in this article, that apart from differences in their interpretations based on their ways of identifying stages in the development of Durkheim's thought, their similarity is to reduce it to a theory of social action.

Keywords: Talcott Parsons. Jeffrey Alexander. The Elementary Forms of Religious Life

\section{L'interminable (faux) débat autour de l'œuvre de Durkheim: de Parsons à Alexander ${ }^{1}$}

\section{Résumé}

Alexander a succédé depuis quelques années à Parsons à titre de sociologue américain le plus influent et, comme Parsons, son œuvre s'est d'abord construite par une réinterprétation critique des auteurs classiques de la sociologie. C'est en grande partie par le biais d'une étude des écrits durkheimiens conférant aux FEVR un statut particulier que les deux auteurs ont élaboré, chacun à leur manière, une théorie volontariste de l'action sociale. Nous verrons dans notre exposé qu'au-delà des différences de leurs interprétations fondées sur leurs manières d'identifier des étapes dans le développement de la pensée durkheimienne, leur similarité est de rabattre celle-ci à une théorie de l'action sociale.

Mots clés : Talcott Parsons. Jeffrey Alexander. Les Formes Élémentaires de la Vie Religieuse.

\footnotetext{
${ }^{1}$ A tradução do original em francês foi realizada por Lucas Page Pereira (PRINTEMPS-UVSQ-CNRS | ENS-Cachan), com revisão de André Magnelli (FSB-RJ | SOCIOFILO-IESP-UERJ | GRECIN-IBMEC-RJ).

N.T. Embora o artigo tenha sido escrito em francês, a totalidade das citações mobilizadas pelo autor estavam, originalmente, em inglês. Para tornar a leitura mais fluida e acessível, optamos
} 
Sociologias, Porto Alegre, ano 19, no 44, jan/abr 2017, p. 92-127

[A] identidade individual representa, assim, uma autonomização de si face à identidade coletiva mais do que o seu contrário, segundo o qual a identidade coletiva resultaria de uma composição de identidades individuais primeiras.

Michel Freitag (2002)

\section{O interminável debate em torno da obra de Durkheim}

Como Alexander escreve em Theoretical Logic in Sociology, "os debates relativos à obra de Durkheim são, inevitavelmente, argumentos relativos às orientações mais fundamentais do pensamento sociológico" (Alexander, 1982, p. 75). Esse comentário é de uma acuidade tal que se aplica precisamente à análise da obra de Durkheim realizada tanto por Alexander, quanto por Parsons. No caso de Alexander, muitos de seus críticos reconhecem de bom grado tal fato. Com efeito, Jonathan Roberge (2009) e Mustafa Emirbayer (2004), para não citar senão eles, estão de acordo quanto à importância da leitura de As Formas Elementares da Vida Religiosa (FEVR) presente em Theoretical Logic para o conjunto dos desenvolvimentos subsequentes da Cultural Sociology de Alexander. Além disso, segundo Emirbayer (2004), é somente após a sua leitura de Saussure, nos anos 1980, que Alexander soube se desfazer da teoria de Parsons, o que exprime toda a importância da leitura de Durkheim por Parsons para a leitura de Durkheim feita pelo jovem Alexander e para os desenvolvimentos subsequentes de sua teoria.

Mas isso nos conduz a questionar-nos quanto ao estatuto e à importância da leitura de Durkheim por Parsons e sobre sua influência em Alexander. Qual é a novidade dessa leitura de Durkheim por Alexander,

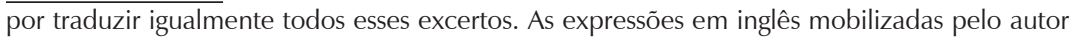
ao longo do artigo, mas que não são propriamente citações, estarão indicadas em itálico. 
comparada àquela feita por Parsons, 50 anos antes? Para responder a essa questão, começaremos pela apresentação da leitura de Durkheim por Parsons. Na sequência, lembraremos as grandes linhas da interpretação de Durkheim por Alexander. Poderemos salientar, então, as críticas formuladas por Alexander à leitura parsoniana de Durkheim, identificar as diferenças de interpretação formuladas por Alexander em Theoretical Logic e, por fim, avaliar as implicações teóricas de tais divergências.

\section{O Durkheim de Parsons: a Estrutura da Ação Social}

A leitura que Parsons faz da evolução da obra de Durkheim tornou-se canônica. Parsons é quem sintetiza melhor a "nova" tendência da recepção dos escritos durkheimianos e quem reorienta mais claramente a discussão sobre o realismo em direção ao aspecto voluntarista. A tese de doutorado de Parsons, publicada em 1937 sob o título A Estrutura da Ação Social, propõe a convergência das teorias clássicas em uma teoria da ação voluntarista e repousa, em grande medida, sobre a identificação de Durkheim com as teorias voluntaristas (Pope, 1973, p.400)².

Lembremos que Parsons corrige a ideia segundo a qual Durkheim seria um teórico da consciência coletiva e afirma que a evolução percebida por ele na teoria de Durkheim torna impossível uma rejeição unilateral da sua obra. A tese de Parsons é a de que Durkheim teria ido do positivismo ao idealismo, passando pelo voluntarismo. No primeiro

\footnotetext{
${ }^{2}$ Segundo Whitney Pope, há sérios erros na análise de Parsons, que se resume nos seguintes termos: "A Estrutura [da Ação Social] busca documentar a emergência da teoria voluntarista da ação a partir de três grandes tradições do pensamento europeu ocidental: o utilitarismo, o positivismo e o idealismo. A ação implica um ator em uma situação orientado para algum fim em que a escolha dos meios é normativamente regulada. (Parsons, 1949: 44-5). Parsons (1949, p. 46) salienta que o quadro de referência da ação é subjetivo no que 'ele lida com fenômenos, com coisas e eventos tais como aparecem do ponto de vista dos atores cuja ação está sendo analisada ou considerada' " (Pope, 1973, p. 399, grifo nosso).
} 
período de sua carreira, Durkheim teria utilizado argumentos positivistas (exterioridade, neutralidade e resistência dos fatos sociais) para atacar o utilitarismo. Somente a partir de 1898, Durkheim começou a tratar os fatos sociais como fenômenos relacionais e psicológicos. Por sua vez, o fim da carreira de Durkheim teria sido marcado pela passagem ao estudo das crenças coletivas como sistemas cognitivos. Segundo Parsons, isso não faz de Durkheim um realista, mas antes um "positivista radical" que teria abandonado essa posição por flertar com o voluntarismo e, depois, adotar uma posição idealista.

Em suma, a leitura parsoniana de Durkheim, em A Estrutura da Ação Social, afirma que a teoria de Durkheim passa de um estágio a outro. Essa leitura se desenvolve e precisa que o desenvolvimento de tal teoria se apresenta em duas fases principais (juventude e velhice) e pode ser subdividido em quatro grandes períodos. Lembremos as etapas pelas quais a teoria durkheimiana teria passado, segundo Parsons. A primeira é aquela da formulação dos "problemas fundamentais" por Durkheim, que descobre a coerção exercida sobre os atores pela realidade social. Trata-se da época de Da Divisão do Trabalho Social (DTS), época do positivismo de Durkheim e de sua fascinação pela exterioridade do social.

A etapa subsequente, aquela da redação de As Regras do Método Sociológico (RMS) e de O Suicídio, é o palco da última síntese histórica durkheimiana. Nela, Durkheim descobre a importância do conteúdo e da força da consciência coletiva. Já a terceira etapa, durante a qual Durkheim redige os textos reunidos em Sociologia e Filosofia e em Educação Moral, é aquela em que se procedeu a descoberta da "interiorização". Este é um período de transição que teria conduzido Durkheim ao reconhecimento da importância da subjetividade e da vontade: "chegando a reconhecer a importância do componente moral interiorizado, Durkheim consegue abranger não somente uma teoria da ação, mas também a sua versão 
voluntarista" (Pope, 1973, p. 400.). Por fim, o quarto e último período, durante o qual Durkheim publica as FEVR, é caracterizado por "investigações empíricas" e culminaria em uma posição idealista.

\subsection{Pope desmascara Parsons}

Mas, como nota Pope, Parsons se contradiz na página 308 de sua tese, ao afirmar que DTS "continha, em germes" os principais desenvolvimentos ulteriores de sua teoria. Segundo Pope, a interpretação de Durkheim por Parsons, a despeito de sua importância, malogrou, pois Parsons não consegue "especificar" as supostas "passagens" ou "etapas" que afirma se sucederem ${ }^{3}$. A crítica de Pope é eloquente e consideramos que ela identifica bem as lacunas da análise de Parsons. Como veremos, mesmo que ele pretenda tergiversar contra as críticas formuladas por Pope, são precisamente essas as lacunas que Alexander quer preencher.

\footnotetext{
${ }^{3}$ Os argumentos de Pope são bem fundamentados e sua apresentação da leitura parsoniana é bem elaborada. Logo na sequência - e isto resulta da qualidade do trabalho de Pope -, Parsons respondeu à crítica tentando, sem muito sucesso, contrapor seus argumentos mais marcantes. Por fim, Parsons não era o único a tentar seccionar a teoria durkheimiana de modo a recuperar uma de suas partes; e a crítica formulada por Pope pode facilmente ser aplicada a Harry Alpert ou Robert Merton. Em resumo, a posição de Pope vai de encontro ao movimento que tenta separar a teoria durkheimiana em períodos, centrando-se em uma crítica do autor que aplica esse tratamento com mais coerência. Talvez seja útil lembrar que o texto original de Pope (1973) esteve na mira de Parsons durante algum tempo, de modo que a réplica de Parsons buscava responder, a um só tempo, aos textos de Pope e de Jere Cohen (1975). Durante o ano de 1975, as hostilidades foram acentuadas por vários eventos. Em fevereiro, foram publicados os comentários de Parsons e a réplica de Pope (1975a) no American Sociological Review (ASR). Mas Pope tinha um interesse explícito no debate e decidiu dar continuidade a sua empreitada. Durante o verão ele publicou Durkheim as a functionalist (1975b) no The Sociological Quarterly e On the divergence of Weber and Durkheim: A critique of Parson's convergence thesis (com Jere Cohen e Lawrence E. Hazelriff, na ASR do mês de agosto). Por fim, em dezembro de 1975, ele publicou um texto sobre o suicídio no British Journal of Sociology, a saber, Concepts and Explanatory Structure in Durkheim's theory of suicide (Pope, 1975c). Não nos ateremos ao conteúdo de cada um desses textos. Não devemos perder de vista aquilo que, de algum modo, fora da temática parsoniana, nos interessa: a similaridade da tática empregada pelos sociólogos americanos para conduzir a eles um pensamento que, a priori, não se presta a isso.
} 
Pope salienta que Parsons hesita entre duas versões do itinerário intelectual de Durkheim: em uma delas, Durkheim teria passado de positivista a idealista "sobrevoando" o voluntarismo. Na outra versão, na última fase, idealista, Durkheim teria sido tentado pelo voluntarismo:

Parsons (1949, p. 445) sustenta que, deixando o positivismo, ele atravessou o voluntarismo para adotar o idealismo. Mas, como idealista, Durkheim presumivelmente não estaria mais próximo da teoria da ação voluntarista do que como positivista. Em outro momento, Parsons (1949: 713) argumenta que, no estágio final do pensamento de Durkheim, idealismo e voluntarismo travavam uma luta acirrada por supremacia. A última visão prevalece. (Pope, 1973, p. 400)

Segundo Pope, essa apresentação dos escritos durkheimianos por Parsons não tem relação com a teoria durkheimiana: ela tem a simples função de demonstrar suas próprias orientações. Durkheim não é um teórico da ação e seu pensamento não evoluiu da maneira indicada por Parsons ${ }^{4}$. A identificação do positivismo como posição inicial de Durkheim, a partir da qual ele passaria logicamente de estado em estado, assume, assim, uma importância particular ${ }^{5}$. Segundo Pope, Durkheim não passou de um estado a outro, posto que ele sequer passou pelo primeiro, o de positivista. Em suma, "Parsons (1949, p. 305, 341) sente que Durkheim começou como um positivista", enquanto Pope sustenta que "Durkheim nunca foi um positivista" (Pope, 1973, p. 400).

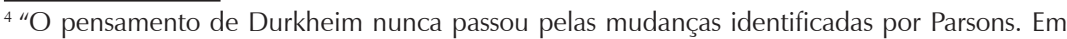
nenhum momento ele adotou qualquer versão da teoria da ação. A interpretação de Parsons frequentemente parece refletir mais sua própria posição teórica do que aquela de Durkheim" (Pope, 1973, p. 400).

${ }^{5}$ É o que explica todo o interesse de teses e artigos questionando o positivismo e o empirismo durkheimiano (Cf. Rafie, 1972, 1981) e sobre o idealismo durkheimiano publicado na segunda metade do século XX. Mais recentemente, Susan Stedman Jones e Yvon Lamy têm, cada um à sua maneira, abordado essa questão e chegado à mesma conclusão, de que Durkheim não era, em todo caso, comtiano (Lamy, 2014; Stedman Jones, 2001).
} 


\subsection{Merton, o positivismo e os dois Durkheims}

Para melhor compreender o que está em jogo na questão do positivismo durkheimiano, é útil nos referirmos a artigos de outros autores publicados antes de A Estrutura da Ação Social de Parsons. Examinando os escritos de Robert Merton, fica patente que a questão do positivismo de Durkheim é importante, por permitir identificar o Durkheim "equivocado", geralmente associado ao livro DTS: "No interior dessa tradição positivista, Divisão [do Trabalho Social] é mais classificável como exemplo da abordagem anti-individualista e anti-intelectualista. É uma revolta declarada contra o positivismo individualista-utilitarista (...)" (Merton, 1934, p.320). Assim, Merton formula implicitamente a tese dos dois Durkheims, vendo no DTS uma abordagem positivista "objetivista" que desapareceria em FEVR (ibid.). Ao final de um resumo do DTS, Merton retorna ao positivismo de Durkheim e às suas consequências: o positivismo de Durkheim é anti-individualista e isso o coloca diante de um dilema:

[Durkheim] defronta-se, consequentemente, com um dilema perturbador: como um positivista, admitir a relevância dos fins para o estudo científico da sociedade; como um anti-individualista, indicar a efetividade dos objetivos sociais no condicionamento da ação social e, por conseguinte, abandonar o positivismo radical (...) Pois, como o positivismo poderia nos fazer crer, se lógica e ciência podem tratar somente de fatos empíricos, sensa, então uma ciência do fenômeno social, só por esse ponto, torna-se impossível, já que esta atitude relega ao limbo todos os fins, isto é, antecipações subjetivas de ocorrências futuras, cuja ausência de consideração torna o comportamento humano inexplicável. (Merton, 1934, p.321)

Lembremos que Merton salienta que o desejo de explicar o social pelo social como a característica distintiva da disciplina sociológica é um ponto comum das doutrinas de Pareto e Durkheim, dois autores positivis- 
tas por excelência (Merton, 1934, p. 323) ${ }^{6}$. Colocando-se explicitamente na perspectiva de Parsons, Merton salienta que é de Parsons que provém a apresentação de Durkheim - e de Pareto - como positivistas. O vínculo entre as proposições de Parsons e as de Merton é, aliás, muito visível na conclusão do artigo deste, que se distancia consideravelmente do vocabulário durkheimiano: "Fins, metas e objetivos são, por definição, não dados lógico-experimentais, mas, sim, julgamentos de valor; e, ainda mais, uma compreensão dos fenômenos sociais requer um estudo de seus papéis" (ibid., p.321) ${ }^{7}$. O principal elemento ao qual Merton se opõe em 1934 é a pretensão durkheimiana de escapar das armadilhas da metafísica evitando tratar os fins. Para ele, essa abordagem não é frutífera: "Banir os fins por eles serem 'impróprios' ao estudo científico não é livrar a sociologia da metafísica, mas viciar suas descobertas com uma metafísica bruta e acrítica" (Ibid., p.322). Em Merton, os "dois Durkheims" estão presentes: como positivista e como anti-individualista. O primeiro Durkheim "baniria" da explicação sociológica os fins individuais para reintroduzir, em seus escritos de "maturidade", os fins sociais:

No tempo de [Da] Divisão [do Trabalho Social], Durkheim era muito positivista para reconhecer toda a força dessa posição, mas suas doutrinas metodologicamente conscientes não resistindo a tal força, ele sub-repticiamente escapa desse dilema e suaviza sua consciência anti-individualista ao tratar dos fins sociais. (Merton, 1934, p. 322)

Os fins sociais se revelam, tanto para Merton quanto para Parsons, na ideia das condições sociais que permitem a relação contratual. Para Durkheim, se a sociedade se reduzisse a relações contratuais interessadas,

\footnotetext{
6"Durkheim e Pareto defendem que o comportamento social não pode ser explicado através da referência ao comportamento individual meramente justaposto. É precisamente essa visão que é sustentada para justificar a sociologia como uma disciplina distinta" (Merton, 1934, p. 323).

${ }^{7}$ Merton aproxima essa visão daquela de Florian Znaniecki e de William I. Thomas em The polish peasant in Europe and America, "Particularmente na discussão das atitudes sociais e na 'definição de situação'" (Merton, 1934, p. 321, nota 4).
} 
ela não seria mais ela mesma (uma sociedade), mas se reduziria ao estado de natureza hobbesiano. Aos olhos de Merton, essa guerra de todos contra todos corresponde à descrição que Durkheim faz da anomia e, mesmo em nossas sociedades individualizadas, esse estado de caos característico das sociedades contratuais não se concretiza, posto que a parte consensual, o complexo de valores sociais mantém a ordem (Merton, 1934).

Mesmo se a quase totalidade do tratamento parsoniano da teoria de Durkheim se encontra condensada nessas poucas observações de Merton sobre o lugar do positivismo na teoria de Durkheim, é somente em 1935 que Parsons publica o argumento no qual se baseia Merton. Contrariamente ao caso Davy/Mauss, ninguém se indigna com o fato de Merton queimar assim as teses de Parsons.

\subsection{Parsons e o positivismo durkheimiano}

Em seu artigo The place of Ultimate Value in sociological theory, Parsons ataca o positivismo por ter afastado a ação humana da reflexão: "A reação positivista contra a filosofia manifestou, nos seus efeitos sobre as ciências sociais, uma forte tendência a obscurecer o fato de que o homem é essencialmente uma criatura ativa, criativa e avaliativa" (Parsons, 1935, p. 282). Na sequência, Parsons precisa as críticas que dirige ao positivismo: tentando reduzir os fins no esquema científico, o positivismo expele completamente o fator dos fins (ibid., p.288) ${ }^{8}$.

Parsons identificava, desde 1935, o que ele qualificaria em sua tese como "primeira etapa" do pensamento de Durkheim: o positivismo. Quando, quarenta anos mais tarde, essa ideia foi atacada por Pope,

\footnotetext{
8 "De fato, muitos teóricos positivistas, por tentarem pensar a ação racional como o tipo inteiramente determinado pelo conhecimento científico e buscarem, assim, encaixar os fins no interior do esquema científico, têm, na verdade, jogado fora todo o fator dos fins (Parsons, 1935, p.288)".
} 
Parsons acreditou que deveria se explicar: "O aspecto positivista do pensamento de Durkheim aparece, sobretudo, em suas reiteradas declarações de que a sociedade deve ser tratada como uma parte da natureza e submetida à mesma ordem de determinismo causal que as demais partes da natureza" (Parsons, 1975, p. 107). Mas a defesa dessa posição por Parsons em 1975 não é muito conclusiva e parece até constituir uma confissão do exagero ao qual ele se rendera. A afirmação de 1937, que parecia fundada sobre poucos fatos, não é mais tão unívoca. Apoiando-se no trabalho de Robert Bellah, Parsons sustenta que: "Minha opinião atual é que Durkheim era profundamente ambíguo a esse respeito (...)"

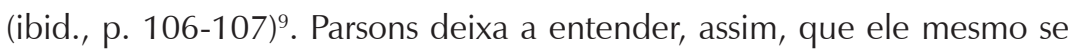
distanciou dessa concepção simplista do positivismo de Durkheim, mas isso sem admitir que, se tal é o caso, o ponto de partida da progressão teórica de Durkheim não é senão uma miragem e que, deste modo, a sucessão das etapas do pensamento durkheimiano que ele propôs não tem fundamento.

\subsection{Um Durkheim voluntarista?}

A despeito das hesitações do pensamento de Parsons no que diz respeito ao positivismo de Durkheim, o que é certo é que a proliferação da tese dos dois Durkheims avançou rápido nos anos 1930. Essa proliferação é visível no fato de encontramos, dentre as críticas que Roscoe Hinkle destaca nos textos de Alpert e de Merton, a não-consideração do esquema fins-meios, enquanto que uma das novidades da recepção de Durkheim à época seria sua associação ao voluntarismo.

9 “D[urkheim], claro, tratou Auguste Comte (1830-1842) como o seu mais importante predecessor; mas Bellah (1973) está igualmente certo ao atribuir uma forte influência à filosofia de Kant (1871)" (Parsons, 1975, p. 107). 
Hinkle apresenta, como primeira prova dessa associação ao voluntarismo, a ideia de Alpert, segundo a qual Durkheim teria sido conduzido a perceber "a incompletude do tipo de análise sociológica que lida exclusivamente com causas e funções" e a preencher essa deficiência recorrendo a "investigações sobre as motivações e a relação meio-fins" (Hinkle, 1960, p. 287, citação de Alpert, 1939, p.111). Mas notemos com Hinkle que, embora seja "sintomática do interesse emergente em Durkheim", a interpretação de Alpert não tem a força das interpretações de Parsons em A Estrutura da Ação Social (1937), que é "inegavelmente um marco na interpretação acadêmica das etapas de desenvolvimento intelectual de Durkheim" e "(...) importante como fonte de impulsos na busca por uma explicação da crescente relevância de D[urkheim] para a sociologia americana" (ibid., p. 280) ${ }^{10}$.

Em A Estrutura da Ação Social, diz Hinkle, Parsons mostra que "um engajamento mais direto com a perspectiva voluntarista da conduta pode ser encontrado no estudo que Durkheim realiza sobre a coerção e o papel do ritual" (Hinkle, 1960, p.287). Essa demonstração da relação direta de Durkheim com "o esquema de meios, condições, fins, normas, bem como a premissa de que a escolha, de certa forma, é onipresente na conduta social" (ibid.), se apresenta como a segunda parte da equação dos dois Durkheims. Essa ideia da "progressão" da teoria durkheimiana persiste nos escritos de Parsons, que a reitera em sua réplica a Pope, em 1975.

Parsons insurge-se contra Pope, por este "atribuir uma rigidez ao trabalho de Durkheim afirmando, essencialmente, que Durkheim nunca mudou seu ponto de vista sobre praticamente nada ao longo de toda sua

\footnotetext{
${ }^{10}$ A tese de Parsons, diz Hinkle, "alinha Durkheim com o voluntarismo pervasivo e contínuo" (Hinkle, 1960 p. 281). Desse modo, é a partir dessa obra-prima de Parsons que Hinkle elabora seus argumentos. Nós, por outro lado, recorremos [também] aos artigos que precedem a publicação de Structure of Social Action e à réplica de Parsons a Pope, em 1975, para ilustrar o vínculo entre os dois Durkheims e seu suposto voluntarismo.
} 
carreira" (Parsons, 1975, p. 106). Embora afirmando que essa posição Ihe parece insustentável, Parsons admite, em meias palavras, ser ela, em parte, verificável: "Talvez eu tenha exagerado um pouco na periodização do desenvolvimento intelectual de Durkheim. Bellah (1973) está certo ao dizer que há uma impressionante continuidade. Por outro lado, parece-me claro que houve um desenvolvimento importante" (ibid., p.106).

\subsection{A terceira forma da coerção como teoria voluntarista}

Em Estrutura da Ação Social, Parsons pretende ilustrar a tese dos dois Durkheims de dois modos. De um lado, apresentando a "terceira" concepção da coerção defendida por Durkheim como a aceitação voluntária ou autoimposição da obrigação moral de obedecer a uma norma. De outro, apresentando o ritual durkheimiano como exigindo a intervenção da vontade ou do esforço. É precisamente essa ideia, desenvolvida por Parsons, que está no centro da interpretação que Alexander faz da teoria durkheimiana.

A tese de Parsons é, portanto, a da passagem de Durkheim de um ponto de vista ao outro. Esta passagem seria visível, segundo Hinkle, no tratamento durkheimiano da coerção: "Na medida em que investiga o problema do controle social, Durkheim muda a base de sua concepção da coerção" (Hinkle, 1960, p. 287). No início, em razão de seu realismo social encarnado em seu positivismo radical, Durkheim teria visto a coerção como o resultado de causas naturais. Em seguida, ele a teria visto como o resultado de evitar as sanções. Finalmente, em um terceiro momento, a coerção seria o resultado da "consciência subjetiva da obrigação moral" (ibid.) ${ }^{11}$. Hinkle resume o ponto culminante do desenvolvimento da coerção durkheimiana na leitura de Parsons dizendo que para este último: "Durkheim vem a conceber a coerção como a aceitação voluntária

$\overline{{ }^{11} \text { Hinkle refere-se a: Parsons: 1937, p. } 385 .}$ 
ou autoimposição da obrigação moral de obedecer a uma norma" (ibid., p. 287). Essa leitura de Hinkle desconhece o artigo de 1975, no qual Parsons, modificando essa posição, admite a persistência do realismo ou do positivismo de Durkheim:

Neste momento, eu quero modificar a posição que tomei em A Estrutura da Ação Social (1937). Ao lidar com o conceito de coerção, eu disse que Durkheim estabeleceu três principais concepções Ipelos fatos do meio-ambiente, pelas sanções das normas e pela autossubmissão à autoridade moral]. Minha mudança de opinião foi que, embora o último conceito se torne central nos trabalhos tardios de Durkheim, de nenhum modo ele abandonou os outros, particularmente o primeiro. (Parsons, 1975, p. 107)

\subsection{A teoria voluntarista do ritual durkheimiano em FEVR}

Em 1935, em um texto ligado à tese defendida em A Estrutura da Ação Social - em que Durkheim é apresentado como um positivista -, Parsons já tentara pôr em destaque as teorias da ação presentes na sociologia continental através de sua interpretação do ritual durkheimiano ${ }^{12}$. Mas, no caso restrito do artigo em questão, o problema mais delimitado que formulava Parsons era saber "Em especial, qual é o estatuto do elemento que pode ser provisoriamente denominado 'valores últimos' naquela concepção [da ação humana]"? (Parsons, 1935, p. 282). A resposta a essa questão passava, de um lado, pelo reconhecimento do vínculo

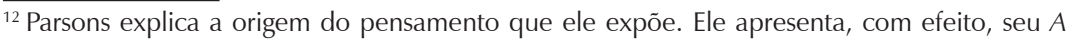
Estrutura da Ação Social: "Minha perspectiva conformou-se principalmente ao longo de uma série de estudos críticos da teoria sociológica europeia. Os autores importantes para os meus propósitos podem ser divididos em dois grupos - aqueles que partem de um background positivista e aqueles que partem de um background idealista. Eu mantenho a tese de que os dois grupos tenderam a convergir para uma concepção relativamente parecida com a que irei descrever no presente ensaio. Dos autores que partem de uma base positivista, dois foram os mais importantes para mim - Vilfredo Pareto e Émile Durkheim. No outro grupo, os mais importantes foram Max Weber, George Simmel e Ferdinand Tönnies" (Parsons, 1935, p. 282-283).
} 
entre a ação e os fins últimos (aquela sendo determinada por esses); e, de outro, pelo reconhecimento do papel importante desempenhado pelos fins coletivos (sistema coletivo ou comum de valores últimos) na vida social e em sua estabilidade:

Assim, na medida em que a ação é determinada por fins últimos, a existência de um sistema de tais fins comuns aos membros da comunidade parece ser a única alternativa ao estado de caos - um fator necessário na estabilidade social (...) Ademais, há muitas evidências empíricas de que tal sistema de fins últimos existe e desempenha um papel decisivo na vida social. (Parsons, 1935, p. 295)

A existência desses sistemas comuns, prossegue Parsons, em nenhum outro lugar é mais bem demonstrada do que na apresentação durkheimiana do caráter comum dos valores individualistas do individualismo moderno.

Mas, talvez, a evidência mais impressionante seja a demonstração empírica, feita por Durkheim, de que mesmo o individualismo moderno, para o qual os utilitaristas têm apontado como a principal confirmação de suas teses, envolveu um valor comum muitíssimo importante, centrando-se, sobretudo, na avaliação ética comum da personalidade individual como tal. (Parsons, 1935, p. 296) ${ }^{13}$

Após ter alegado a presença desses sistemas de valores comuns e a importância de seu papel na teoria de Durkheim, Parsons busca demonstrar, na interpretação durkheimiana do ritual, o voluntarismo que dele resulta. O ritual, diz ele, é "governado" por normas ${ }^{14}$. Essa interpretação do significado do ritual durkheimiano permite a Parsons afirmar que tudo o que ele faz é seguir o pensamento do chefe da Escola Francesa de So-

\footnotetext{
${ }_{13}^{13}$ Parsons se refere especialmente a DTS (livro I, cap. 1) e a O Suicídio (livro III, cap. 1). 14 “O caráter especial da relação de meios-fins simbólicos ajuda a explicar dois traços peculiares do ritual religioso. Uma vez que ele é uma forma de ação da vida séria, ele deve ser pensado como sendo governado por normas" (Parsons, 1935, p. 303).
} 
ciologia, desenvolvendo, dessa forma, sua teoria da ação: "Foi Durkheim, em FEVR, quem, do ponto de vista sociológico, primeiro expôs estritamente esse aspecto do ritual religioso" (Parsons, 1935, p. 305, nota 18):

Assim, a ação religiosa forma, juntamente com a ação na busca imediata de fins empíricos últimos e com as instituições, o terceiro aspecto da incidência dos fins últimos sobre a vida social. (...) Esses três fenômenos não devem ser entendidos primordialmente como três "fatores" separados da vida social, mas, sim, como três modos de expressão - em diferentes relações com a ação - do mesmo fator fundamental - o sistema de valores comuns últimos (Parsons, 1935, p. 305, grifo nosso). ${ }^{15}$

Assim, antes mesmo da publicação de A Estrutura da Ação Social, Parsons tinha tentado ilustrar o voluntarismo presente em FEVR mostrando que o ritual religioso está sob influência de normas estritas que permitem aos atores orientarem suas práticas e ações utilizando o esquema fins/ meios. No período posterior, os argumentos de Parsons evoluíram e ele veio a perceber o voluntarismo durkheimiano em funcionamento em $O$ Individualismo e os Intelectuais, além de aprofundar sua apresentação da concepção durkheimiana da religião e da coerção, interessando-se mais pela interiorização [das normas], que é concebida como autopoiesis dos sistemas vivos, e pela integração dos conceitos cibernéticos na descrição sociológica (Lafontaine, 2004).

\section{O Durkheim de Alexander: theoretical logic in sociology}

A tese defendida por Alexander é a seguinte: o jovem Durkheim desejava resolver o problema da modernidade, a saber, juntar determinismo e voluntarismo, altruísmo e egoísmo. Todavia, a teoria de Durkheim

$\overline{{ }^{15} \text { Parsons se refere }}$ aqui a uma passagem de FEVR (p. 546). 
passou por uma série de etapas antes de chegar a uma formulação teórica satisfatória. Alexander identifica quatro períodos importantes: 1. os trabalhos de juventude (1887-1893); 2. a primeira obra de maturidade: Da Divisão do Trabalho Social (1893); 3. o período intermediário (18941897); 4. o período final, durkheimianismo tardio (1898-1917).

Em sua juventude (período 1, 1887-1893), Durkheim oscila entre determinismo e voluntarismo, mas tende ao determinismo. Por outro lado, Durkheim ataca os pontos de vista que negligenciam a vontade individual. Os trabalhos preparatórios do DTS, especialmente aqueles que resultam da viagem de Durkheim à Alemanha, testemunham essa indecisão.

O segundo período (período 2, 1893), que Alexander identifica ao DTS, testemunha essa ambivalência. O capítulo 5 do livro mostra, segundo Alexander, os esforços de Durkheim para se desvencilhar do determinismo, através de uma concepção da ordem social emanando da ação voluntarista, enquanto o resto da obra mostra fortes tendências deterministas. Na última parte do livro (livro 3), Durkheim retorna, com efeito, a uma teoria determinista, posto que ele se vê incapaz de explicar as formas anormais da divisão do trabalho social sem recorrer à coerção.

O período intermediário (período 3, 1894-1897), que vai de As Regras do Método Sociológico até O Suicídio, marca uma busca de compromisso. A periodização proposta por Alexander confere a RMS um estatuto especial, posto que ele vê nessa obra o ponto de inflexão da carreira de Durkheim. Em RMS, diz-nos Alexander, Durkheim estabeleceria uma teoria da ação social e da ordem com fortes tendências subjetivistas. É em torno da definição de fatos sociais como representações que se dá a passagem do determinismo ao voluntarismo. Esse primeiro ponto de inflexão, prossegue Alexander, concretiza-se em uma teoria geral, no momento da famosa revelação provocada pela leitura de William Robertson Smith, em 1895. A partir desse momento, nos diz Alexander, é toda a 
sociedade que será vista por Durkheim como um fenômeno religioso. Segue-se daí que a redação de O Suicídio por Durkheim não é, aos olhos de Alexander, senão a concretização dessa nova teoria voluntarista.

A partir de 1898 (período 4, 1898-1917), o desencadear da carreira de Durkheim não é senão uma sequência de provas de sua passagem cada vez mais afirmada ao voluntarismo. Os trabalhos de maturidade, tais como abordados por Alexander, são apenas consequências da teoria da religião desenvolvida por Durkheim a partir de 1898 e que, dado que ela não mudará mais, se realizará plenamente em As Formas Elementares da Vida Religiosa, em 1912. A ordem social, segundo essa teoria em que a religião ocupa um lugar privilegiado, não é nada além do resultado das ações voluntárias cristalizadas.

Assim, a particularidade da cronologia estabelecida por Alexander, mesmo se ele deixa subentender que somente os escritos de maturidade são pertinentes, repousa principalmente sobre uma leitura dos três primeiros períodos.

\section{Alexander a respeito de Parsons}

As críticas e os elogios que Alexander dirige à tese de Parsons são tão variados que é difícil, à primeira vista, apreender o julgamento que ele faz de Parsons - quem, aliás, é elevado ao grau de autor clássico da sociologia no quarto volume de Theoretical Logic in Sociology. Isso porque, ainda que reconhecendo os méritos da tese de Parsons e nela se inspirando, Alexander tenta desenvolver uma análise original e indica que sua própria interpretação das tensões no desenvolvimento do pensamento de Durkheim difere de maneira fundamental daquelas de Parsons e de Steven Lukes. O debate, em suma, concerne sobretudo à periodização do desenvolvimento teórico da obra de Durkheim. 
Com efeito, para além de algumas críticas menores, o que sobressai do uso que Alexander faz da interpretação parsoniana de Durkheim é mais do que um sentimento de gratidão em relação a Parsons - que seria o único dos "primeiros intérpretes" a não sucumbir à tendência de atribuir uma "falsa" continuidade à teoria de Durkheim ${ }^{16}$.

Nesse sentido, é a "lição de lógica teórica" dada por Parsons em A Estrutura da Ação Social que está no centro da interpretação de Durkheim por Alexander e na origem das críticas que este dirige aos outros intérpretes da obra durkheimiana. Essa "lição" - que se resume à injunção de não confundir os conceitos que remetem a fenômenos concretos com aqueles que remetem a conceitos teóricos abstratos - é, com efeito, aquela que Alexander estima ter tomado para si. Ademais, essa apropriação é de tal ordem que ele volta contra Parsons o seu próprio argumento, criticando-o por ter aproximado demasiadamente a ordem e a ação a ponto de Ihes confundir ${ }^{17}$.

Alexander critica vários outros (especialmente Pope) por não terem compreendido essa lição de Parsons. Para Alexander, se eles tivessem compreendido o argumento de Parsons, tenderiam a uma visão mais evolutiva da obra de Durkheim. Aliás, o principal mérito da interpretação que Parsons faz de Durkheim é ter conseguido demonstrar que Durkheim atribui uma importância cada vez maior ao voluntarismo e à normatividade na explicação da ordem social e da ação social.

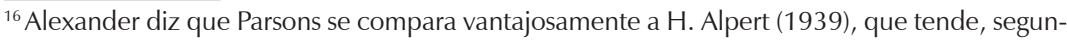
do Alexander, a ver continuidade na obra de Durkheim (o que, em minha tese de doutorado, mostro que é um equívoco). Robert Nisbet concorda com Parsons, assim como e Steven Lukes, embora este último não se reconheça em dívida com Parsons.

${ }^{17}$ A confusão em torno da questão da ordem em Durkheim está ligada à interpretação de Parsons, que distingue a preocupação de Durkheim com a estabilidade empírica e a sua orientação ideológica. Assim, Parsons confunde a solução geral que Durkheim dá ao problema da ordem (que, segundo Alexander, ele ilustra bem) com uma preocupação quanto ao equilíbrio empírico concreto (Alexander, 1982, p. 78). Aliás, o pensamento de Parsons é ele próprio fragmentado pela mesma tensão que enfraquece a teoria de Durkheim: sua ambição de integração e de síntese estava minada por sua tendência ambivalente a reduzir a ordem coletiva a uma cultura ensinada na afetividade. Em suma, Parsons não soube tampouco resolver as tensões da teoria que Durkheim nos legou (ibid., p. 326-327).
} 
A genialidade de Parsons, diz Alexander, é ter enfrentado o problema do voluntarismo separando a essência da teoria geral de Durkheim de toda a relação necessária com seu método positivista. Combinando Freud e Durkheim, Parsons conseguiu articular explicitamente a interdependência e a autonomia relativa da personalidade e dos códigos culturais, podendo falar de indivíduo "socializado" de uma maneira menos reificada. Sensível ao idealismo problemático de Durkheim, Parsons tentou integrar a concepção durkheimiana de ordem normativa e a teoria weberiana da coerção. A teoria que resulta desse esforço, que gira em torno da independência analítica da cultura e do sistema social, pôs em questão o significado durkheimiano da "sociedade", de modo a resolver os dilemas do pensamento durkheimiano (Alexander, 1982, p. 326-327).

Por outro lado, é precisamente na demonstração dessa evolução da teoria durkheimiana por Parsons que Alexander vê lacunas.

\subsection{As lacunas da análise parsoniana do desenvolvimento teórico do pensamento durkheimiano}

Parsons conseguiu, assim, mostrar a atitude mutável de Durkheim relativamente ao indivíduo e aos fatores externos. Todavia, Alexander identifica limites à análise de Parsons (Alexander, 1982, n. 83, p. 470). Primeiramente, sua explicação dessa mudança e a identificação do momento em que ela se produz: segundo Parsons, a mudança deveu-se à confrontação de Durkheim com os fatos empíricos. O Suicídio seria contraditório em razão das compreensões empíricas oporem-se ao determinismo que resulta da metodologia positivista de Durkheim (Parsons, 1937, pp. 343, 376). Segundo Alexander, a posição metodológica de Durkheim nunca mudou e é por isso que Parsons não pode apresentar a prova conclusiva de sua interpretação. O que mudou em Durkheim não é o seu ponto de vista do mundo empírico a-teórico, mas sim sua 
concepção geral da ação e da ordem - que era gerada por condições não empíricas e não científicas.

Em segundo lugar, Parsons não compreende a posição normativa de Durkheim, porque a vê não como uma proposição interessante e importante ao ponto de vista de Durkheim com base em uma dimensão da ordem social, mas como uma explicação da ordem coletiva em si. Infelizmente, diz Alexander, é essa interpretação que encontramos em quase todas as tentativas de explicação do verdadeiro estatuto normativo da associação no período intermediário dos escritos durkheimianos, sobretudo nos EUA.

\subsection{Uma posição positivista?}

Segundo Alexander, a ideia de que o pressuposto instrumentalista presente na obra de Durkheim se deve ao seu positivismo metodológico é largamente aceita, por corresponder a um erro arraigado na tradição teórica ocidental. Ainda mais, a principal fonte de tal erro é a obra de Parsons, para quem: 1. Durkheim confundiu a aceitação científica da lei natural com uma perspectiva mecanicista da natureza da ação humana em si; e 2. Durkheim só se desvencilha do instrumentalismo na medida em que ele se afasta dessa posição metodológica, e esse movimento é impulsionado pela força inelutável dos fatos empíricos (Alexander, 1982, n. 18, p. 462). Alexander não está de acordo com essa concepção, especialmente quando se trata dos escritos de juventude de Durkheim.

\subsection{A juventude de Durkheim em questão}

Os trabalhos de juventude de Durkheim, segundo Alexander, lançam uma nova luz sobre o seu desenvolvimento, especialmente sobre o livro Da Divisão do Trabalho Social. Por um lado, a similaridade temática entre os escritos de juventude e os escritos de maturidade invalida o cor- 
te epistemológico que Parsons e Lukes veem se produzir em 1897. Por outro lado, nesse período de juventude, as ideias esparsas são uma prova a mais da falsidade da tese de um desenvolvimento unilateral da teoria de Durkheim. Somente tomando em conta esses trabalhos de juventude, pode-se compreender porque Durkheim se volta ao DTS em 1893, e avaliar o longo desenvolvimento teórico que lhe dá recursos para operar sua virada decisiva, logo na sequência da publicação de DTS.

\subsection{As provas da inexatidão da tese do Durkheim unificado mesmo no interior da DTS}

A ambivalência da análise efetivada por Durkheim no Livro I de DTS invalida as teses de que seu pensamento é unificado (por exemplo, aquelas de Anthony Giddens, Mark Traugott e Jean-Claude Filloux $)^{18}$. Parsons faz melhor, mas se equivoca ao tentar moralizar o tema dominante, ao fazer uma leitura errônea de certos capítulos do DTS (especialmente o capítulo 7, do livro I), e afirmando que o elemento não-contratual do contrato é, na verdade, o problema original de que se ocupa Durkheim ao longo de todo o DTS (Alexander, 1982, n. 129, pp. 426-427).

Para Parsons, esses elementos não-contratuais são sinônimos das regras morais, e essa abordagem se opõe àquela utilitarista que contrapõe os interesses dos indivíduos aos do Estado. Segundo apresenta Alexander, uma das razões dessa leitura é o fato de Parsons ter ignorado os desenvolvimentos teóricos de Durkheim anteriores a 1893: Parsons pensa que a teoria de Durkheim se desenvolve de modo linear desde sua juventude,

\footnotetext{
${ }^{18}$ Segundo esses autores, Durkheim teria apresentado um argumento teórico satisfatório no que diz respeito às bases das sociedades modernas. O julgamento de Giddens implica que Durkheim teria resolvido o dilema indivíduo/sociedade. Para Giddens, a tese principal do DTS é que "a individualização é necessariamente concomitante à dissolução da sociedade tradicional" e que isso implica não a erradicação completa da consciência coletiva, mas, sim, sua transmutação no desenvolvimento de um novo ideal moral, incluso no culto do indivíduo. Filloux pensa que Durkheim persiste na mesma posição normativa, Traugott pensa que Durkheim persiste na mesma posição materialista (Alexander, 1982, n. 129 p. 426-27).
} 
quando ele exibe um positivismo racionalista, até sua maturidade, em que adota uma posição mais subjetiva e normativa. Parsons apresenta a posição do jovem Durkheim levando em conta somente o DTS, mas, para Alexander, antes de 1893, Durkheim estava extremamente dividido entre duas posições antitéticas desde o princípio - aliás, Parsons não apreende a importância da estadia de Durkheim na Alemanha (1886-1887) para o seu pensamento como um todo, já que pensa que seu positivismo o tornava impermeável ao idealismo alemão (Alexander, 1982, n. 129, p. 427).

Na realidade, segundo Alexander, a orientação teórica de Durkheim antes de 1893 era instrumentalista e o desafio de DTS era o de resolver o problema voluntarismo/coletivismo no interior dessa abordagem. Nesse contexto, a ênfase nos elementos não-contratuais do capítulo 7 diz respeito à natureza da ordem legal instrumental e do controle coercitivo do Estado - e não, como pensava Parsons, à ordem normativa.

É no capítulo 5 (e não no capítulo 7), que Durkheim dá sua contribuição mais importante a uma teoria da ordem moral moderna - aliás, é em sua questão central, a da diferenciação moral, que Parsons se atém em sua análise (relativamente) tardia da teoria durkheimiana (1960). Parsons tem razão ao ver as primeiras discussões de Durkheim sobre a consciência coletiva e sobre a solidariedade mecânica como estando ligadas a considerações tanto históricas quanto teóricas fundamentais. Ainda assim, ele não consegue explicar por que essa ênfase desaparece progressivamente ao longo da obra. Às vezes, Parsons afirma que isso se deve à decisão ad hoc de Durkheim de se restringir à lei como indicador da moralidade, decisão que o conduz à dicotomia histórica que ele exprime sob a forma da oposição entre lei repressiva e lei restitutiva. Segue-se dessa lacuna na análise de Parsons ao tratar do livro II de DTS como uma forma anormal da análise durkheimiana. Já, para Alexander, o livro II conteria, ao contrário, o principal argumento de DTS. Tudo isso explica porque Parsons 
não discute o conteúdo do livro III, que é ainda mais instrumental que os livros I e II (Alexander, 1982, n. 129, p. 427) ${ }^{19}$.

Segundo Alexander, o livro III desempenha um papel interessante na teoria sociológica do pós-guerra, e isso é outra indicação do fato de que as leituras interpretativas são elementos estratégicos cruciais da teorização sociológica (Alexander, 1982, n.163, p. 432-433) ${ }^{20}$. A esse respeito, o ponto de vista liberal adotado por Parsons não é defendido por Alexander. Parsons escreve que Durkheim, em DTS, embora se oponha a Spencer e a sua explicação da estabilidade das sociedades contemporâneas, não duvida dessa estabilidade - prova disso seria, para Parsons, a brevidade da discussão das formas anormais por Durkheim. Ora, para Alexander, as reservas de Durkheim face a Spencer são justamente ligadas ao fato de Durkheim perceber melhor do que Spencer as instabilidades das sociedades modernas (Alexander, 1982, n.163, pp. 432-433).

Em suma, Parsons se perde em sua interpretação do primeiro Durkheim, porque negligencia os escritos de juventude e não analisa bem a ambivalência da teoria que se desenvolve no interior de DTS. O suposto positivismo de Durkheim não é tão evidente quanto Parsons afirma.

\footnotetext{
${ }^{19} \mathrm{~A}$ respeito das interpretações do livro II, Alexander nos diz que os comentadores postulam a equivalência entre densidade moral e densidade demográfica e, por conseguinte, veem o livro II como sendo plenamente coerente com os elementos de ordem normativa que estão no livro I. Pope, por exemplo, pensa que a ênfase na expansão da população e das trocas não é senão um exemplo do realismo social que domina todo o trabalho de Durkheim. Essa perspectiva, segundo Alexander, comete o erro de reagrupar e confundir os problemas da ordem e da ação e, assim, não conseguem distinguir as abordagens radicalmente diferentes da ação que são possíveis no quadro de uma posição sociorrealista coletivista (Alexander, 1982, n. 162, pp. 430-31).

${ }^{20}$ David Lockwood e Alvin Gouldner, dois teóricos críticos, valem-se da ênfase instrumentalista do pensamento normativo de Durkheim para se oporem ao funcionalismo normativo de Parsons e dos funcionalistas americanos. Gouldner se opõe a Parsons, questionando a filiação comteana do pensamento durkheimiano. Apesar da pertinência de sua apreensão dos elementos antinormativos do livro III, a leitura desses pensadores está errada por: 1. ver no livro III uma análise multidimensional, quando, na realidade, trata-se de uma leitura anti-voluntarista unidimensional; 2. veem no livro III o protótipo das análises do jovem Durkheim. Tais leituras não cometem, no entanto, erros tão grandes quanto aquele de Friedmann (Alexander, 1982, n. 163, p. 432-433).
} 


\subsection{Os trabalhos do "período intermediário" em questão:} a importância da "revelação"

A reação de Alexander à interpretação dos escritos do período intermediário por Parsons é também muito crítica, embora seja o ponto de partida de sua própria análise.

Contrariamente a Gouldner, que se baseia em $O$ socialismo para argumentar que Parsons erra ao interpretar Durkheim como dando ênfase à integração moral, Alexander pensa que esta obra demonstra, precisamente, o que teria dito Parsons. Com efeito, em O socialismo, diz Alexander, Durkheim apresenta uma mudança fundamental em sua leitura da modernidade, resultado da especificação empírica da posição geral que ele teria adotado no ano precedente (em RMS). Efetivamente, diz Alexander (1982, p. 467), a autonomia da consciência torna-se cada vez mais importante nos trabalhos subsequentes. O problema, para ele, é que Parsons vê o RMS como um livro do jovem Durkheim, apresentando uma posição instrumentalista e positivista.

Mas isso não significa que Parsons tenha realizado um trabalho completamente inútil, ao contrário. É por não seguirem a lição de Parsons e, assim, agrupar e confundir as questões da ordem e da ação, que os críticos recentes podem ler Durkheim como tendo uma visão instrumentalista da ordem, o que é o contrário do que ele tenta fazer em seu período intermediário ${ }^{21}$.

\footnotetext{
${ }^{21}$ Peter Blau interpreta a ênfase dada por Durkheim à coerção e à exterioridade como se ela se referisse às pressões concretas dos grupos concretos, à estruturação dos valores pela sanção material - por oposição a uma ênfase na estrutura dos valores pela interiorização. Segundo Alexander, é precisamente contra esse tipo de reificação que Durkheim tentava se premunir. Blau revela, assim, sua incapacidade de compreender a visão do indivíduo social, que permitia ao Durkheim do período intermediário evoluir em direção de uma teoria da ordem mais voluntarista. É o tipo de leitura - à la Blau - que motivou Durkheim a evoluir para um idealismo assumido. Além disso, ver Durkheim como um materialista faz com que confundamos seu engajamento empírico e ideológico perante uma visão secular com seu engajamento perante os pressupostos materialistas - enquanto que, segundo Alexander, a resposta teórica de Durkheim ao marxismo é um idealismo pós-teológico. Aron comete o mesmo erro ao escrever
} 
Segundo Alexander, o problema de Durkheim é a natureza da interação social, não o fato de existir tal interação. Nos trabalhos do período intermediário, afirma Alexander, a abordagem do problema socioestrutural por Durkheim evoluiu resolutamente para uma compreensão normativa. A passagem foi efetuada em RMS e determinou a abordagem utilizada por Durkheim em O Suicídio (Alexander, 1982, n.82, p.469)22. É a esse respeito que Parsons se engana em um primeiro momento, não apreendendo essa passagem rápida de Durkheim para uma teoria normativa.

Para Alexander, a comparação entre o texto de 1888 sobre o suicídio e a obra de 1897 é a melhor maneira de ver o progresso de Durkheim - embora Lukes e Filloux vejam sobretudo uma continuidade entre os

que Durkheim "tende a tomar o milieu social por uma realidade sui generis objetivamente e materialmente definido, enquanto que, de fato, ele é uma representação intelectual". Uma vez mais, segundo Alexander, é justamente contra esse tipo de erro reificante que Durkheim lutou durante seu período intermediário. Pope comete também esse erro ao escrever que Durkheim não se interessava pelo conteúdo valorativo da cultura, mas somente pela sua capacidade de controlar a ação individual do exterior. Alexander afirma que Pope toma Durkheim por um determinista, enquanto, de fato, Durkheim está a caminho de tornar-se voluntarista. Isso se deve ao erro de lógica teórica cometido por Pope ao pensar que o voluntarismo só pode ser combinado à coerção se a ação individual é baseada no cálculo racional de vantagens e inconvenientes das regras sociais. Tudo isso faz com que Pope não compreenda corretamente os ataques de Durkheim à subjetividade, que não são uma rejeição da ação normativa, mas sim uma rejeição da ideia de que a individualidade aleatória poderia ser a fonte da ordem. Embora Alexander não considere Pope errado ao criticar Parsons, não é menos verdade que Pope demonstra não ter compreendido nada da brilhante lição teórica de Parsons. Aliás, Pope também comete o erro de apresentar Durkheim como um realista social antissubjetivo na leitura que faz de O Suicídio, na qual afirma que Durkheim se afasta do argumento morfológico desenvolvido em DTS (Alexander, 1982, n. 82, p. 469).

${ }^{22}$ Segundo Alexander, Alpert seria um dos primeiros a ter defendido a continuidade da tese normativa de Durkheim, mostrando que a sua análise associativa é, a um só tempo, normativa e coerente com o voluntarismo: ela seria uma tentativa de superar, ao mesmo tempo, o realismo e o normativismo. O problema, segundo Alexander, é que Alpert pretende que Durkheim teria sempre tido essa intuição. Por sua vez, Bellah diz praticamente a mesma coisa ao afirmar que a teoria de Durkheim apresenta uma continuidade certa. Mas, de todo modo, ele faz uma notável análise da relação entre simbolismo e interação iniciada por Durkheim nos trabalhos do período intermediário. Filloux, igualmente, faz em "Durkheim et le socialisme" uma bela discussão da "associação efetiva" nos trabalhos do período intermediário, mas peca ao afirmar que essa perspectiva está presente ao longo de toda a carreira de Durkheim (Alexander, 1982, n. 83, p. 471). 
dois textos, considerando o primeiro como o precursor lógico e empírico do livro de 1897. Alexander sustenta que, no artigo de 1888, Durkheim evoca dois fatores quase-instrumentalistas como fatores explicativos, a saber, o desequilíbrio objetivo dos grupos sociais e a dificuldade da luta pela existência. Em O Suicídio, esses dois fatores são substituídos pela força ou pela fraqueza relativas da solidariedade subjetiva e se opõem explicitamente à ideia de que as dificuldades objetivas da luta pela vida poderiam explicar o suicídio (Alexander, 1982, n. 83, p. 470)23.

A conclusão preliminar a que se pode chegar é que Alexander se apoia em Parsons para construir sua tese geral, mas se distancia dele quando se trata de apresentar a evolução da tese de Durkheim e seu resultado: as divergências surgem, especialmente, em relação aos escritos de juventude, do "período intermediário". Resta-nos, agora, ver a posição de Alexander sobre o idealismo que Parsons julga característico do último período ("Durkheim tardio").

\section{Desvendando o lugar da religião: FEVR e a fase de desenvolvimento do pensamento de Durkheim a que corresponde essa obra}

O maior problema que Alexander diz encontrar na interpretação dessa fase é o de se tomar a questão que interessava Durkheim nos termos marxistas da relação entre base e superestrutura ${ }^{24}$. Para Alexander, o

\footnotetext{
${ }^{23}$ Parsons vê melhor que Alpert essas tensões em curso em O Suicídio. Alpert tenta explicar a reificação contínua do social como uma estratégia na qual se adota o pensamento utilitarista para melhor refutá-lo (Alexander, 1982, n. 107, p. 478).

${ }^{24}$ Os exemplos desse tipo de abordagem são numerosos. Émile Benôit-Smullyan escreve a respeito da relação crucial entre o substrato material e as representações coletivas. Pope pergunta-se se as fundações materiais desempenhavam algum papel. Giddens tenta indicar o impacto contínuo das instituições sociais sobre as ideias de Durkheim - impacto este que exemplificaria seu anti-individualismo. A mesma dicotomia organiza o pensamento de Lukes em relação à vi-
} 
verdadeiro problema da confrontação de Durkheim com a religião não é o de saber se a base material predomina sobre a estrutura (questão resolvida desde 1894); mas, sim, a da natureza da concepção da ordem normativa que Durkheim adotará.

\subsection{O lugar de "A definição do fenômeno religioso" e os dois cortes}

A maior parte das interpretações não veem a importância e o significado particular do primeiro encontro de Durkheim com a religião. Parsons pensa que é somente em FEVR que a religião passa a desempenhar um papel relevante na teoria de Durkheim. Para Alexander, é impressionante que Parsons tenha conseguido descrever a transição para a subjetividade no período intermediário sem compreender o significado dessa primeira interpretação do papel da religião para Durkheim ${ }^{25}$.

A exceção mais notável a essa tendência a não compreender o sentido da importância da religião na teoria durkheimiana é aquela da tese de Bernard Lacroix, a quem Alexander dirige duas críticas principais. Primeiramente, mesmo se Lacroix apresenta o corte criado no desenvolvimento teórico de Durkheim pela revelação religiosa, aquele tenta excessivamente associá-la ao período intermediário, enquanto que, para Alexander, a teoria de Durkheim sofre dois cortes após publicação do DTS (e não um

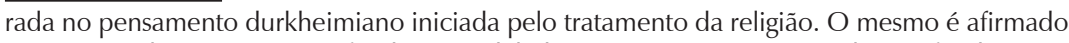
por Dominick La Capra e, no fundo, o modelo base-superestrutura é aquele que fundamenta os trabalhos de Stephen Marks, Gouldner etc. Essas interpretações, ainda que tomem posições diferentes sobre a questão da continuidade da obra de Durkheim, cometem todas o mesmo erro aos olhos de Alexander (1982, n. 185, p. 489).

${ }^{25}$ Lukes, que é o mais consciente desse fato biográfico crucial, não considera esse avanço religioso como uma linha de análise separada das outras, que culmina no FEVR e que só se integra muito mal com os escritos de Durkheim sobre a educação, a política e as outras instituições (Alexander, 1982, n.185, p. 489). Claude Lévi-Strauss, Rodney Needham e Jean Duvignaud se opõem à teoria do ritual de Durkheim. Isso porque, para eles, Durkheim postula que os sentimentos, puramente "ideais sociais" dos indivíduos, são sempre do mesmo gênero e que isso não permite explicar as diferentes formas de simbolização geradas pela vida religiosa (Ibid.).
} 
único, como defende Lacroix), a saber, uma reorganização subjetivista radical da teoria sem referência às representações coletivas ou à religião (1893-1894); e aquela que confere um lugar central às considerações espirituais no quadro dessa teoria novamente subjetivada. Este último corte - de caráter religioso, pouco visível em O socialismo e que se tornará explícito somente a partir de 1897 - é o único que pode, segundo Alexander, ser associado à "revelação" de 1895. Em segundo lugar, a tese de Lacroix não ilustra de maneira satisfatória a dimensão religiosa da teoria institucional do "Durkheim tardio".

\subsection{Vínculos entre a concepção durkheimiana da religião e da modernidade segundo Alexander}

Para Giddens, o FEVR não mudaria nada nas teorias de Durkheim sobre a modernidade, já que diria respeito somente às sociedades primitivas e à solidariedade mecânica. Essa leitura, segundo Alexander, negligencia a amplitude dos efeitos da revelação de 1895. Durkheim já tinha adotado uma leitura normativa e afetiva antes de sua leitura de William Robertson Smith. O interesse com o qual Durkheim recebeu essa teoria deve-se às similaridades da obra de Smith com a nova direção dada por Durkheim a sua própria obra. É essa similaridade que permitiu a Durkheim reinterpretar sua nova orientação teórica nos termos religiosos que Smith the forneceu ${ }^{26}$.

\footnotetext{
${ }^{26}$ Mesmo se o significado dos ritos e crenças e o caráter comum da vida ritual fossem as ideias mais desenvolvidas de Smith sobre a religião, ao menos dois outros elementos de sua teoria foram importantes para o desenvolvimento da teoria de Durkheim. Em primeiro lugar, a definição da sacralidade como uma relação mais à divindade do que uma qualidade intrínseca dos objetos. Em seguida, a ideia de que nas religiões antigas existe uma relação sagrada entre a forma material e a substância espiritual. Assim, Smith não forneceu a Durkheim sua compreensão inicial do fundo emotivo e normativo da associação e da ordem social. Mas sua compreensão da religião permitiu a Durkheim conceber a ordem sob uma forma religiosa. Particularmente do ponto de vista da religião, Durkheim guarda, entretanto, certos elementos da teoria de Smith, sobretudo no que diz respeito à natureza da religião primitiva e à sua relação com as religiões modernas (Alexander, 1982, n. 176, p. 484).
} 


\subsection{Robertson Smith e a revelação}

Graças a Smith, Durkheim pode ver claramente que a solidariedade social era o objeto do ritual e que o divino era um meio para os homens representarem, uns aos outros, a experiência da sociedade. Durkheim pôde, assim, compreender o processo de representação que transforma a associação em experiência religiosa. Antes de sua leitura de Smith, Durkheim já tinha compreendido o papel primordial da solidariedade na criação das formas institucionais. Esse fato, somado ao seu interesse de longa data pela consolidação e a salvaguarda da ação voluntarista, o fez concentrar-se na criação dos deuses pelos homens. Do mesmo modo, sua convicção quanto à eficácia do poder moral e afetivo das formas cristalizadas - em particular aquele de estimular a ação social -, tornava-o sensível ao papel das crenças na experiência religiosa. Assim, Durkheim radicalizou Smith ao dizer que religiões primitivas e avançadas eram praticamente idênticas; e que tais práticas religiosas eram características do funcionamento das sociedades seculares em geral ${ }^{27}$.

Como todos aqueles que não compreenderam a tese de Parsons, Georges Gurvitch cometeu o erro (de ordem teórico-lógica) de confundir o indivíduo analítico e o indivíduo concreto. Ele afirma que Durkheim via a consciência individual como fechada, impenetrável e, a partir disso, concluiu que Durkheim concebia a consciência coletiva de forma exterior e reificada. No entanto, segundo Alexander, desde RMS e O Suicídio, ao tratar de uma consciência individual fechada, Durkheim não se refere ao

\footnotetext{
${ }^{27}$ Beidlmani exagera o efeito de Smith sobre Durkheim, porque não leva em conta os desenvolvimentos ocorridos na teoria durkheimiana antes da leitura de Smith. Lukes faz a mesma coisa, porque se limita a uma comparação da teoria religiosa de Durkheim antes e depois da leitura de Smith, sem levar em conta os desenvolvimentos ocorridos na mesma antes da leitura de Smith. Filloux, por sua vez, diz que Durkheim manteve a mesma posição ao longo de toda sua carreira: Durkheim teria tido o sentimento de que "tudo é religioso" já em 1886-1887. Quanto a Jones, ele vê os efeitos da leitura de Smith mostrarem-se nos escritos de Durkheim somente a partir de 1900 (Alexander, 1982, n. 176, p. 484).
} 
ator concreto (claramente social em sua individualidade), mas, sim, ao indivíduo no sentido analítico (que é um ator privado e a-social).

Em suma, segundo Alexander, certas ambiguidades persistem na teoria durkheimiana da consciência individual, mas isso o conduz a uma direção quase-utilitarista e não, como deixa entender Gurvitch, a uma direção idealista - e como sugere igualmente Parsons, embora Alexander não o diga.

5.4. Uma teoria emergentista para ir de encontro à tese parsoniana do idealismo de Durkheim em FEVR

Alexander não está convencido do idealismo do "velho" Durkheim. Mas, Lukes, La Capra e Parsons, diz ele, apresentam como provas de que Durkheim teria transcendido o idealismo sociológico somente o papel que este atribui às instituições sociais e às interações individuais (Alexander, 1982, n. 23, p. 403), o que não é suficiente. Parsons tem o mérito de ter lançado as bases de um acordo entre DTS e os trabalhos mais tardios, onde uma ênfase cultural é mais visível, mas, na medida em que o trabaIho de Parsons revela uma redução idealista, ele não ecoa a interpretação de Alexander (Alexander, 1982, n. 130, p. 519).

A teoria durkheimiana do ritual é, segundo Alexander, a seguinte: o ritual implica o sentimento e o afeto, mas essa emoção é sempre fortemente afetada pelas formas ideacionais cristalizadas pelas associações prévias e estruturadas em uma situação particular pelo processo de ideação cognitiva ativa que Durkheim denomina representação (Alexander, 1982, n. 185, p. 489). Por sua vez, Alexander espera - demonstrando, como fizera Parsons, o aspecto voluntarista da teoria durkheimiana do ritual - conseguir desvelar a falsidade das análises que apresentam o Durkheim de FEVR como um idealista anti-individualista. 


\section{Conclusão}

6.1. Os excessos da interpretação de Alexander: o paralelo com o interacionismo simbólico e o pragmatismo

Alexander pensa que o sentido conferido por Durkheim à cognição individual ativa em sua análise das práticas rituais tornou-se evidente, devido ao seu acordo com certas noções centrais das teorias contemporâneas desenvolvidas na tradição do interacionismo simbólico inspirado pelo pragmatismo. Nesse sentido, afirma Alexander, Georges H. Mead era sensível ao estatuto "realista" da ordem simbólica: "o ativismo" da teoria simbólica de Mead seria, assim, coerente com a teoria durkheimiana das representações coletivas elaboradas pelo velho Durkheim.

Alexander sublinha igualmente a necessidade de se fazer o paralelo entre Durkheim e Charles Peirce. Segundo Alexander, a prova desse paralelo seria que, inspirando-se em Peirce, Charles Morris desenvolveu uma teoria dos signos e símbolos muito importante para os desenvolvimentos teóricos que Alexander considera "durkheimianos", por exemplo, aqueles de Edward Shils e Parsons.

Todo esse raciocínio de Alexander é absurdo... Mas, independentemente disso, para Alexander, uma aproximação entre Durkheim e as tradições contemporâneas mais individualistas depende não só de uma maior apreciação do ativismo cognitivo em vigor na teoria das representações de Durkheim; mas, também, de uma compreensão mais "realista" das dimensões coletivistas dos fundadores do interacionismo contemporâneo (Alexander, 1982, n. 185, p. 489).

Não sou um especialista em Mead, mas sei que algumas passagens de sua obra dão, efetivamente, margem a uma interpretação mais "realista" do que aquela que geralmente prevalece. Por outro lado, somos forçados a admitir que o raciocínio de Alexander é duvidoso: pretender 
que a prova que valida sua apresentação de Durkheim resida nos vínculos que alguns autores vislumbram entre os escritos durkheimianos e a tradição pragmático-interacionista, não é um argumento conclusivo. Aliás, Alexander derroga nesse ponto o procedimento que pôs em prática ao longo de toda a obra, a saber, uma análise muito criteriosa dos textos durkheimianos. Por que, quando chega o momento de tratar a relação de Durkheim com o pragmatismo, Alexander não se refere à obra póstuma de Durkheim sobre o pragmatismo? Sem dúvida, porque as críticas de Durkheim a essa doutrina vão de encontro à interpretação de Alexander!

\subsection{A importância da interpretação do papel da religião}

Mostramos que é no quadro da interpretação do papel que desempenha a religião na teoria durkheimiana que a tese de Alexander se distancia daquela de Parsons. Para Alexander, as ideias de Durkheim sobre a religião the permitiram desenvolver uma teoria casando o voluntarismo e o determinismo de maneira satisfatória, sob uma forma que podemos qualificar de emergentismo. Em suma, Durkheim teria descoberto que as estruturas são o resultado da ação voluntária. A importância, para Alexander, dessa "verdade" é de tal ordem que ele precisa contestar a vertente da interpretação parsoniana que aproxima Durkheim de um idealismo tardio. O mesmo vale para a possibilidade de "recuperar" Durkheim.

6.3. O exagero das críticas sobre a cronologia para esconder a convergência fundamental da apresentação da teoria durkheimiana como uma teoria voluntarista da ação

Alexander exagera consideravelmente ao afirmar que sua interpretação difere fundamentalmente daquela de Parson. É evidente, ao fim desta apresentação da obra de Durkheim por Parsons e por Alexander, que os dois autores compartilham a mesma leitura geral da teoria durkheimiana: 
Alexander tenta esconder uma floresta recorrendo a algumas árvores. Em última análise, tudo o que Alexander faz visa confrontar a tese de Parsons - segundo a qual Durkheim é, antes de qualquer coisa, um teórico da ação que propõe uma abordagem voluntarista -, cujo objetivo subjacente é claramente o de se apropriar da figura durkheimiana para legitimar sua própria abordagem.

6.4. O papel da interpretação dos clássicos: o monopólio do discurso legítimo sobre a ortodoxia do campo

Sem pretender engajar-nos em um debate de interpretação da obra de Durkheim, convém salientar que as abordagens de Parsons e de Alexander são idênticas em buscarem se apropriar do discurso legítimo sobre a doxa do campo sociológico para, no final, içar suas próprias teorias ao patamar dos "pais fundadores". Além disso, devemos constatar que essa empreitada é bastante vitoriosa. Se, a partir de Parsons, admitiu-se ler Durkheim como um teórico da ação, hoje é impossível passar ao largo da versão alexanderniana dessa mesma tese. Não somente a Cultural Sociology e o "programa forte" de Alexander são muito populares, mas, também, uma pluralidade de autores (John Rawls, etc.) alimenta doravante essa leitura do "pai fundador" da sociologia francesa, de tal modo que a sociologia contemporânea é resolutamente antirrealista e esqueceu-se completamente que, em outra época, foi articulada em torno de uma posição menos monoliticamente voluntarista.

De Parsons até Alexander, as principais teorias postas em destaque são teorias da ação precisamente no sentido parsoniano: elas dizem respeito a atores em situações orientadas para um fim em um quadro em que a seleção dos meios é normativamente regulada. Ademais, não se deve, sobretudo, ver nessa regulação normativa uma concessão à ideia de uma realidade social qualquer agindo: em última análise, como Parsons 
salientara, o quadro de referência da ação é sempre subjetivo, posto que é constituído por fenômenos tais como aparecem do ponto de vista do ator cuja ação é analisada. Uma vez que esse ponto de vista foi adotado, não resta senão renunciar ao projeto durkheimiano e resignar-se a produzir uma "sociologia sem sociedade".

François Pizarro-Noël é professor associado do Departamento de Sociologia e Estudos Religiosos na Université du Québec à Montréal (UQAM), Canadá. $>$ pizarro-noel.francois@uqam.ca

\section{Referências}

1. ALEXANDER, J.C. Theoretical Logic in Sociology. Vol. Two. The Antinomies of Classical Thought: Marx and Durkheim. Berkeley/Los Angeles: University of California Press, 1982.

2. ALPERT, H. Émile Durkheim and His Sociology. New York: Columbia University Press, Russell \& Russell, 1966 [1939].

3. COHEN, J. Moral Freedom Through Understanding in Durkheim. American Sociological Review, v. 40., n.1, pp.104-106, Feb. 1975.

4. EMIRBAYER, M. The Alexander School of Cultural Sociology. Thesis Eleven, $n$. 79, pp. 5-15, 2004.

5. FREITAG, M. Actualité de l'animal, virtualité de l'homme. Entrevista com Michel Freitag. Comentários colhidos por Le Collectif. Conjonctures. n³3-34, pp. 99-154, outono de 2001/inverno de 2002.

6. HINKLE, R.C. Durkheim in American Sociology. In: WOLFF, K. Émile Durkheim 1858-1917, Ohio State University Press, pp. 267-295, 1960.

7. LAFONTAINE, C. L'empire cybernétique: des machines à penser à la pensée machine. Paris: Seuil, 2004.

8. LAMY, Y. Les Formes élémentaires de la vie religieuse et le rapport Comte/ Durkheim : une filiation problématique. Cahiers de recherche sociologique, $v$. 56, pp. 53-86, 2014.

9. MERTON, R.K. Durkheim's Division of Labor in Society. American Journal of Sociology, v. 40, n. 3, pp.319-328, 1934. 
10. PARSONS, T. Comments on 'Parsons' Interpretation of Durkheim' and on 'Moral Freedom through Understanding in Durkheim'. American Sociological Review, v. 40, n. 1, pp.106-111, Feb. 1975.

11. PARSONS, T. The Structure of Social Action. New York: Free Press, 1937.

12. PARSONS, T. The place of Ultimate Value in sociological theory. International Journal of Ethics. v. 45, n.3, pp. 282-316, abr. 1935.

13. POPE, W. Parsons on Durkheim, Revisited. The American Sociological Review, v. 40, n.1, pp. 111-115, 1975a.

14. POPE, W. Durkheim as a Functionalist. The Sociological Quarterly, v. 16, summer, pp. 361-379, 1975b.

15. POPE, W. Concepts and Explanatory Structure in Durkheim's Theory of Suicide. The British Journal of Sociology, v. 26, n. 4, pp. 417-434, 1975c.

16. POPE, W. Classic on Classic: Parsons' Interpretation of Durkheim. American Sociological Review, v. 38, n. 4, pp.399-415, August, 1973.

17. POPE, W.; COHEN, J.; HAZELRIGG, L.E. On the Divergence of Weber and Durkheim : A Critique of Parsons Convergence Thesis. The American Sociological Review, vol. 40, no. 4, August, 1975, p. 417-427.

18. RAFIE, M. Le Suicide, empirie et... métaphysique. Sociologie du Sud-est, n. 30, oct-déc, pp.41-62, 1981.

19. RAFIE, M. Positivisme chez Émile Durkheim. Sociologie et sociétés, v. IV, n. 2, pp.275-287, 1972.

20. ROBERGE, J. Alexander, Jeffrey C. et les dix ans du programme fort en sociologie culturelle. Cahiers de recherche sociologique, n. 47, pp. 47-66, 2009.

21. STEDMAN-JONES, S. Durkheim Reconsidered. Cambridge: Polity Press, 2001.

Recebido: 02.08.2016

Aceito: 24.10 .2016 